\title{
Head phantoms for bioelectromagnetic applications: a material study
}

\author{
Alexander Hunold ${ }^{1 *}\left(\mathbb{B}\right.$, René Machts $^{1}\left[\right.$ and Jens Haueisen $^{1,2}$ []
}

\section{*Correspondence:}

alexander.

hunold@tu-ilmenau.de

'Institute of Biomedical

Engineering and Informatics,

Faculty of Computer Science

and Automation, Technische

Universität Ilmenau,

98693 IImenau, Germany

Full list of author information

is available at the end of the article

\begin{abstract}
Background: Assessments of source reconstruction procedures in electroencephalography and computations of transcranial electrical stimulation profiles require verification and validation with the help of ground truth configurations as implemented by physical head phantoms. For these phantoms, synthetic materials are needed, which are mechanically and electrochemically stable and possess conductivity values similar to the modeled human head tissues. Three-compartment head models comprise a scalp layer with a conductivity range of $0.137 \mathrm{~S} / \mathrm{m}$ to $2.1 \mathrm{~S} / \mathrm{m}$, a skull layer with conductivity values between $0.066 \mathrm{~S} / \mathrm{m}$ and $0.00275 \mathrm{~S} / \mathrm{m}$, and an intracranial volume with an often-used average conductivity value of $0.33 \mathrm{~S} / \mathrm{m}$. To establish a realistically shaped physical head phantom with a well-defined volume conduction configuration, we here characterize the electrical conductivity of synthetic materials for modeling head compartments. We analyzed agarose hydrogel, gypsum, and sodium chloride ( $\mathrm{NaCl})$ solution as surrogate materials for scalp, skull, and intracranial volume. We measured the impedance of all materials when immersed in $\mathrm{NaCl}$ solution using a four-electrode setup. The measured impedance values were used to calculate the electrical conductivity values of each material. Further, the conductivities in the longitudinal and transverse directions of reed sticks immersed in $\mathrm{NaCl}$ solution were measured to test their suitability for mimicking the anisotropic conductivity of white matter tracts.
\end{abstract}

Results: We obtained conductivities of $0.314 \mathrm{~S} / \mathrm{m}, 0.30 \mathrm{~S} / \mathrm{m}, 0.311 \mathrm{~S} / \mathrm{m}(2 \%, 3 \%, 4 \%$ agarose), $0.0425 \mathrm{~S} / \mathrm{m}$ and $0.0017 \mathrm{~S} / \mathrm{m}$ (gypsum with and without $\mathrm{NaCl}$ in the compound), and $0.332 \mathrm{~S} / \mathrm{m}(0.17 \% \mathrm{NaCl}$ solution). These values are within the range of the conductivity values used for EEG and TES modeling. The reed sticks showed anisotropic conductivity with a ratio of 1:2.8.

Conclusion: We conclude that agarose, gypsum, and $\mathrm{NaCl}$ solution can serve as stable representations of the three main conductivity compartments of the head, i.e., scalp, skull, and intracranial volume. An anisotropic conductivity structure such as a fiber track in white matter can be modeled using tailored reed sticks inside a volume conductor.

Keywords: Conductivity, Anisotropy, Impedance spectroscopy, EEG, TES, Agar hydrogel

(c) The Author(s) 2020. This article is licensed under a Creative Commons Attribution 4.0 International License, which permits use, sharing, adaptation, distribution and reproduction in any medium or format, as long as you give appropriate credit to the original author(s) and the source, provide a link to the Creative Commons licence, and indicate if changes were made. The images or other third party material in this article are included in the article's Creative Commons licence, unless indicated otherwise in a credit line to the material. If material is not included in the article's Creative Commons licence and your intended use is not permitted by statutory regulation or exceeds the permitted use, you will need to obtain permission directly from the copyright holder. To view a copy of this licence, visit http://creativecommons.org/ licenses/by/4.0/. The Creative Commons Public Domain Dedication waiver (http://creativecommons.org/publicdomain/zero/1.0/) applies to the data made available in this article, unless otherwise stated in a credit line to the data. 


\section{Background}

Technologies such as transcranial electric stimulation (TES), transcranial current density imaging (CDI), and neuronal source imaging based on electroencephalography (EEG) and magnetoencephalography (MEG) require methodologies for verification and validation. The evaluation of new measurement and analysis chains can be addressed by (i) computational modeling and simulation [1] and (ii) metrological inspections $[2,3]$. Computational modeling and simulations provide a convenient way of assessing the above technologies. However, only metrological inspections allow the inclusion of real-world environmental influences and allow the validation of computational modeling and simulations based on ground truth.

For EEG/MEG, the spread of electromagnetic fields caused by intracranial generators is of high importance for the identification of bio-electric sources [4]. For TES, dosage considerations require exact knowledge of the spread of the electromagnetic field inside the head [5]. In both applications, the computation of the electromagnetic field requires a thorough knowledge of the volume conductor, i.e., the 3D conductivity profile within the human head. The geometry is commonly segmented from magnetic resonance imaging data sets [6] and the conductivity values are derived from literature. These values demonstrate large variations resulting from inter- and intraindividual variations [7] and differences in experimental methodology [8] and do not necessarily match the individual conductivity profiles $[7,8]$.

For evaluating the methodologies introduced above, using a physical phantom of the head as a volume conductor can overcome most uncertainties that occur. The geometry of the phantom is predefined by the design and manufacturing processes and the conductivity properties of the phantom materials can be measured in advance.

The skull serves as the major conductivity barrier in the human head. Consequently, there are three compartments of particular interest: scalp (soft tissue outside of the skull), skull, and intracranial volume [9]. The soft tissue compartments with higher conductivity encase the skull compartment with low conductivity. A widely used conductivity value for the intracranial volume is $0.33 \mathrm{~S} / \mathrm{m}$ [10]. According to literature, the ratio for the skull-to-soft tissue conductivity ranges from 1:120 [11] to 1:5 [12]. A further feature of interest for physical representation is conductivity anisotropy, which occurs mainly in the fiber tracts of white matter. The anisotropy ratio between the longitudinal and transverse direction in white matter was varied from 1:2 to 1:100 in modeling studies [13, 14]. Nicholson found an anisotropy ratio of approximately 1:9 in impedance measurements of the white matter in cats [15].

Previous approaches used head phantoms based on post-mortem human skulls for the assessment of EEG source reconstruction procedures [16, 17], doped saline solution for the verification of TES simulations $[18,19]$, and human torso built from guar gum for the modeling of conductive anisotropy [20]. These phantoms incorporated saline solutions with different electrolyte concentrations to obtain different conductivity values. Interfacing multiple compartments with different saline solutions introduces concentration gradients leading to diffusion processes. The time-dependent electrolyte diffusion limits the stability of the respective conductivity configurations in such phantoms.

Our goal is to establish a stable and well-characterized setup for physical head phantom measurements. In this study, we aim to establish and characterize suitable synthetic 
materials that allow the fabrication of a multi-compartmental and realistically shaped human head phantom with inherently different conductivities that has a homogeneous electrolyte concentration within compartments and will not be affected by diffusion of ions between compartments. The skull, which serves as a major structural conductivity barrier is based on a material that is plastically formable during manufacturing to replicate a realistic geometry. This material should be mechanically stable enough to serve as a support structure for adjacent compartments. Similarly, the material for the scalp should provide mechanical stability, allowing the attachment of electrodes for measurements or stimulation. For the intracranial volume, we required a material that allows for easy insertion of structures for signal generation (dipoles) or measurements (electrode arrays).

\section{Results}

\section{Sodium chloride solution}

The $0.17 \% \mathrm{NaCl}$ solution provided conductivities of $0.299 \mathrm{~S} / \mathrm{m} \pm 0.005 \mathrm{~S} / \mathrm{m}$ (mean $\mu \pm$ standard deviation $\sigma$ ) on the ProfiLine Cond 3310 ( $0.5 \%$ uncertainty) at temperatures of $20.04{ }^{\circ} \mathrm{C} \pm 0.70{ }^{\circ} \mathrm{C}$. With temperature compensation to $25{ }^{\circ} \mathrm{C}$ at the ProfiLine Cond 3310 , conductivities of $0.333 \mathrm{~S} / \mathrm{m} \pm 0.001 \mathrm{~S} / \mathrm{m}$ were measured in $0.17 \% \mathrm{NaCl}$ solutions, in line with previously published data [21]. Considering an inner electrode distance of $25 \mathrm{~mm}$ and a tube diameter of $58 \mathrm{~mm}$ in the experimental setup (Fig. 8), the reference impedance of the $0.17 \% \mathrm{NaCl}$ solution was calculated from the conductivity to be $31.69 \Omega$ at $20{ }^{\circ} \mathrm{C}$ and $28.45 \Omega$ at $25^{\circ} \mathrm{C}\left(\mathrm{Z}_{25 \mathrm{ref}}\right)$. The measured impedance of the reference $0.17 \% \mathrm{NaCl}$ solutions in the four-electrode [22] setup was $31.41 \Omega \pm 0.14 \Omega\left(\mathrm{Z}_{\text {meas }}\right)$ which resulted in a conductivity value of $0.301 \mathrm{~S} / \mathrm{m} \pm 0.002 \mathrm{~S} / \mathrm{m}$ (cf. Eq. 2). During these measurements, the temperature in the $0.17 \% \mathrm{NaCl}$ solutions was $21.04{ }^{\circ} \mathrm{C} \pm 0.18{ }^{\circ} \mathrm{C}$ $\left(\vartheta_{\text {meas }}\right)$. We determine the cell constant $\alpha$ for the four-electrode setup to -0.026 . The cell constant was calculated from Eq. 1 using $Z_{25 \text { ref }}, Z_{\text {meas }}$, and $\vartheta_{\text {meas }}$ from the impedance measurements with only $0.17 \% \mathrm{NaCl}$ solution in the cell.

After applying Eq. 1 to adjust for the differences in the temperature at the time of measurement, the impedance of $0.17 \% \mathrm{NaCl}$ solution was equivalent of $28.39 \Omega \pm 0.19 \Omega$ at $25{ }^{\circ} \mathrm{C}$, which is a conductivity of $0.332 \mathrm{~S} / \mathrm{m} \pm 0.003 \mathrm{~S} / \mathrm{m}$. These values were found to be consistence for frequencies of $0.1 \mathrm{~Hz}$ to $100 \mathrm{kHz}$ (Fig. 1 top) and at $1 \mathrm{~Hz}$ over $10 \mathrm{~min}$ (Fig. 1 bottom).

\section{Agar hydrogel}

The $2 \mathrm{wt} \%$ agar hydrogel in $0.17 \% \mathrm{NaCl}$ solution $(n=3)$ has a conductivity of $0.284 \mathrm{~S} / \mathrm{m} \pm 0.009 \mathrm{~S} / \mathrm{m}$ at $21.05{ }^{\circ} \mathrm{C} \pm 0.23{ }^{\circ} \mathrm{C}$, which is equivalent of $0.314 \mathrm{~S} / \mathrm{m} \pm 0.01 \mathrm{~S} / \mathrm{m}$ at $25{ }^{\circ} \mathrm{C}$ (adjusted using Eq. 1). The $3 \mathrm{wt} \%$ agar $(n=3)$ has a conductivity of $0.272 \mathrm{~S} / \mathrm{m} \pm 0.005 \mathrm{~S} / \mathrm{m}$ at $20.99{ }^{\circ} \mathrm{C} \pm 0.19{ }^{\circ} \mathrm{C}$, which is equivalent of $0.302 \mathrm{~S} / \mathrm{m} \pm 0.005 \mathrm{~S} / \mathrm{m}$ at $25{ }^{\circ} \mathrm{C}$ (adjusted using Eq. 1). The $4 \mathrm{wt} \%$ agar $(n=3)$ has a conductivity of $0.281 \mathrm{~S} / \mathrm{m} \pm 0.02 \mathrm{~S} / \mathrm{m}$ at $20.88^{\circ} \mathrm{C} \pm 0.41{ }^{\circ} \mathrm{C}$, which is equivalent of $0.311 \mathrm{~S} / \mathrm{m} \pm 0.018 \mathrm{~S} / \mathrm{m}$ at $25{ }^{\circ} \mathrm{C}$ (adjusted using Eq. 1). These values were found to be consistent for frequencies of $0.1 \mathrm{~Hz}$ to $100 \mathrm{kHz}$ (Fig. 2 top) and at $1 \mathrm{~Hz}$ over $10 \mathrm{~min}$ (Fig. 2 bottom). 


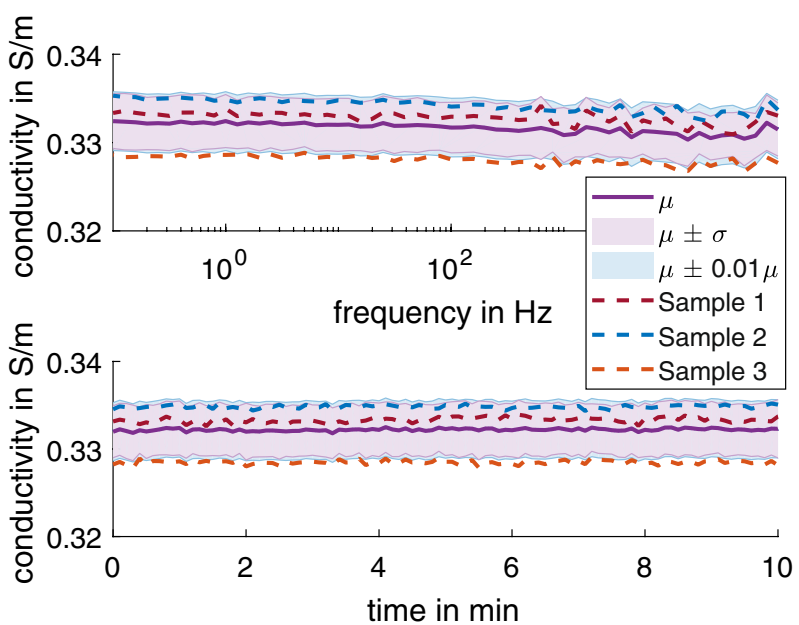

Fig. 1 The average conductivity data $(n=3)$ at $25^{\circ} \mathrm{C}$ of $0.17 \% \mathrm{NaCl}$ solution (top) for $0.1 \mathrm{~Hz}-100 \mathrm{kHz}$ and (bottom) at $1 \mathrm{~Hz}$ for $10 \mathrm{~min}$. The dashed line shows the average for each sample taken over three series of measurements taken with $30 \mathrm{~min}$ in between. The shaded regions show $\mu \pm \sigma$ (purple) and $\mu \pm 0.01 \mu$ (blue) for comparison

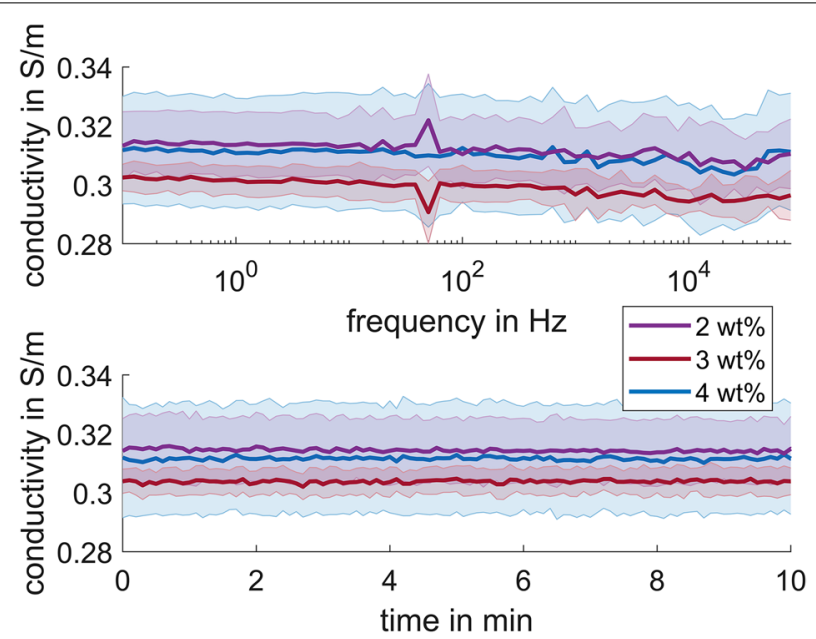

Fig. 2 The average conductivity of $2 \mathrm{wt} \%(n=3), 3 \mathrm{wt} \%(n=3)$, and $4 \mathrm{wt} \%(n=3)$ agar in $0.17 \% \mathrm{NaCl}$ solution adjusted to $25^{\circ} \mathrm{C}$ for (top) frequencies of $0.1 \mathrm{~Hz}$ to $100 \mathrm{kHz}$ and (bottom) $1 \mathrm{~Hz}$ for $10 \mathrm{~min}$. Three series of measurements were done for each sample with $30 \mathrm{~min}$ in between. The shaded regions show $\mu \pm \sigma$

Even though measurements were conducted in a grounded Faraday cage, the spike at $50 \mathrm{~Hz}$ in the spectra (Fig. 2 top) was likely due to power-line interference.

The $2 \mathrm{wt} \%$ agar was also tested for an extended frequency range of $0.01 \mathrm{~Hz}$ to $100 \mathrm{kHz}$ (Fig. 3 top) and duration of $60 \mathrm{~min}$ at $10 \mathrm{~Hz}$ (Fig. 3 bottom). The conductivity was found to stay consistent in this extended range, with $0.276 \mathrm{~S} / \mathrm{m} \pm 0.006 \mathrm{~S} / \mathrm{m}$ at $20.76{ }^{\circ} \mathrm{C} \pm 0.1{ }^{\circ} \mathrm{C}$, equivalent of $0.306 \mathrm{~S} / \mathrm{m} \pm 0.007 \mathrm{~S} / \mathrm{m}$ at $25^{\circ} \mathrm{C}$ (adjusted using Eq. 1). 


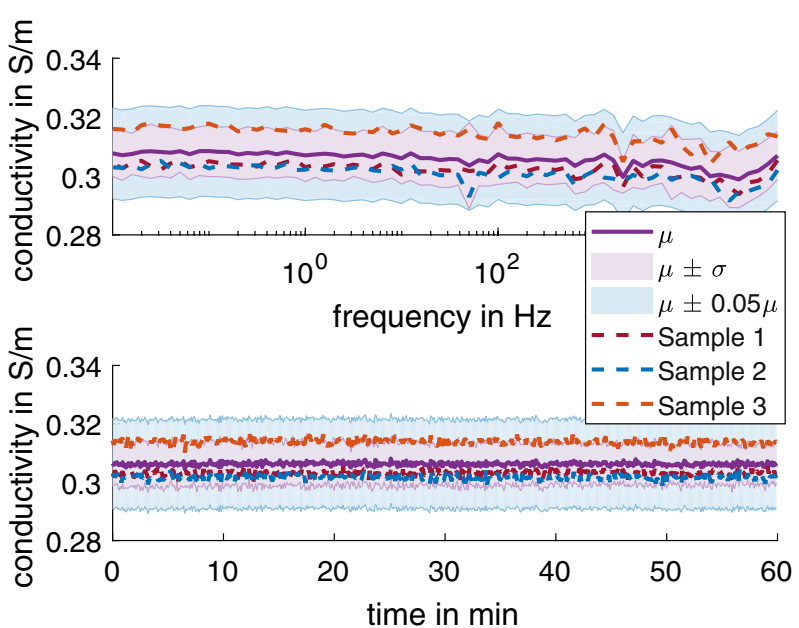

Fig. 3 The average conductivity of $2 \mathrm{wt} \%$ agar in $0.17 \% \mathrm{NaCl}$ solution adjusted to $25^{\circ} \mathrm{C}$ for the (top) extended frequency range of $0.01 \mathrm{~Hz}$ to $100 \mathrm{kHz}$ and (bottom) extended duration of $60 \mathrm{~min}$ at $10 \mathrm{~Hz}$. The dashed line shows the data for each sample as color-coded. The shaded regions show $\mu \pm \sigma$ (purple) and $\mu \pm 0.05 \mu$ (blue) for comparison

\section{Gypsum}

Three series of measurements (sample immersed in $0.17 \% \mathrm{NaCl}$ solution) were made on one sample of Stewaform gypsum without $\mathrm{NaCl}$ in the casting compound (Fig. 4). The sample was let rest in ambient air for $20 \mathrm{~h}$ between measurements.

The gypsum sample demonstrated a capacitive character with increasing conductivity for frequencies above $1 \mathrm{kHz}$, such that the phase decreased from -8 degrees at $1 \mathrm{kHz}$ to -50 degrees at $100 \mathrm{kHz}$. For quantitative evaluations, the frequency range up to $1 \mathrm{kHz}$ was considered. The sample has an average conductivity of $0.0016 \mathrm{~S} / \mathrm{m} \pm 0.0009 \mathrm{~S} / \mathrm{m}$ at $25^{\circ} \mathrm{C}$ for frequency up to $1 \mathrm{kHz}$. Given the dry initial condition of the gypsum, the first series of measures was an outlier with $0.0008 \mathrm{~S} / \mathrm{m} \pm 0.0001 \mathrm{~S} / \mathrm{m}$ at $25^{\circ} \mathrm{C}$ while the following two series of measures averaged to $0.0017 \mathrm{~S} / \mathrm{m} \pm 0.00004 \mathrm{~S} / \mathrm{m}$ at $25^{\circ} \mathrm{C}$.

Three series of measurements (sample immersed in $0.17 \% \mathrm{NaCl}$ solution) were made on one sample of Stewaform gypsum with $\mathrm{NaCl}$ in the casting compound (Fig. 5). The sample was let rest in ambient air for $20 \mathrm{~h}$ between measurements. This gypsum sample has a conductivity of $0.037 \mathrm{~S} / \mathrm{m} \pm 0.0012 \mathrm{~S} / \mathrm{m}$ at $18.85{ }^{\circ} \mathrm{C} \pm 0.19{ }^{\circ} \mathrm{C}$, which is equivalent of $0.043 \mathrm{~S} / \mathrm{m} \pm 0.0015 \mathrm{~S} / \mathrm{m}$ at $25^{\circ} \mathrm{C}$ (adjusted using Eq. 1).

Three samples of gypsum with $\mathrm{NaCl}$ in the casting compound were tested for an extended frequency range of $0.01 \mathrm{~Hz}$ to $100 \mathrm{kHz}$ (Fig. 6 top) and duration of $60 \mathrm{~min}$ at $10 \mathrm{~Hz}$ (Fig. 6 bottom). The conductivity was found to stay consistent in this extended range, with $0.037 \mathrm{~S} / \mathrm{m} \pm 0.002 \mathrm{~S} / \mathrm{m}$ at $19.75{ }^{\circ} \mathrm{C} \pm 0.26{ }^{\circ} \mathrm{C}$, equivalent of $0.042 \mathrm{~S} / \mathrm{m} \pm 0.003 \mathrm{~S} / \mathrm{m}$ at $25^{\circ} \mathrm{C}$ (adjusted using Eq. 1).

\section{Conductivity anisotropy}

Five series of measurements (sample immersed in $0.17 \% \mathrm{NaCl}$ solution) were made on the tube cell configuration (Fig. 8 bottom) holding 80 reed sticks for frequencies of 

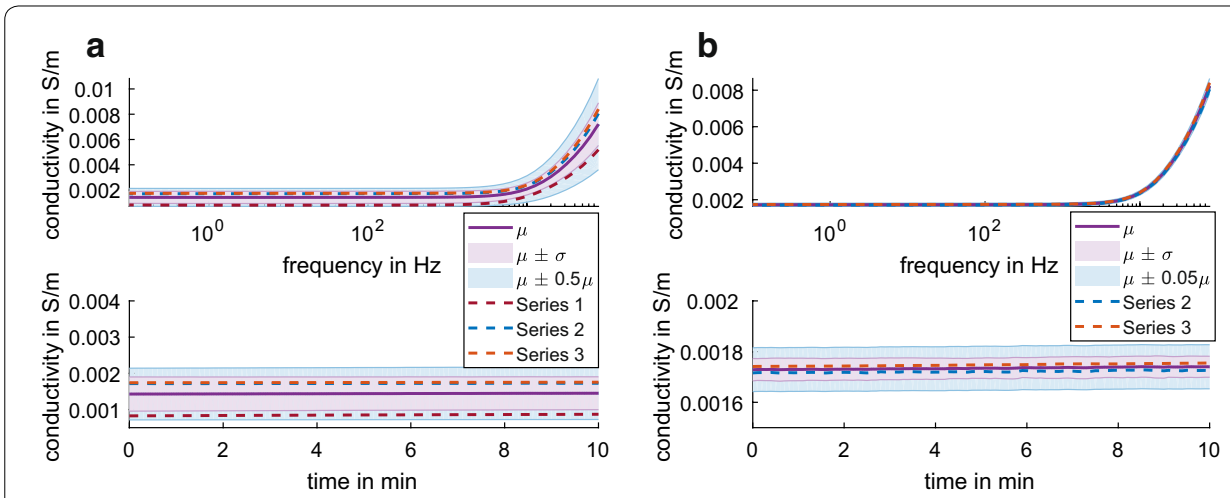

Fig. 4 The conductivity of the gypsum sample without $\mathrm{NaCl}$ in the casting compound a average over all three series of measurements (color-coded dashed lines) in $0.17 \% \mathrm{NaCl}$ solution adjusted to $25^{\circ} \mathrm{C}$ and b average with the outlier (series 1 ) removed is shown on the right. The conductivity is shown for (top) frequencies of $0.1 \mathrm{~Hz}$ to $100 \mathrm{kHz}$ and (bottom) $1 \mathrm{~Hz}$ for $10 \mathrm{~min}$. The shaded regions show $\mu \pm \sigma$ (purple) and $\mu \pm 0.5 \mu$ (blue) for comparison on the left and $\mu \pm 0.05 \mu$ (blue) for comparison on the right

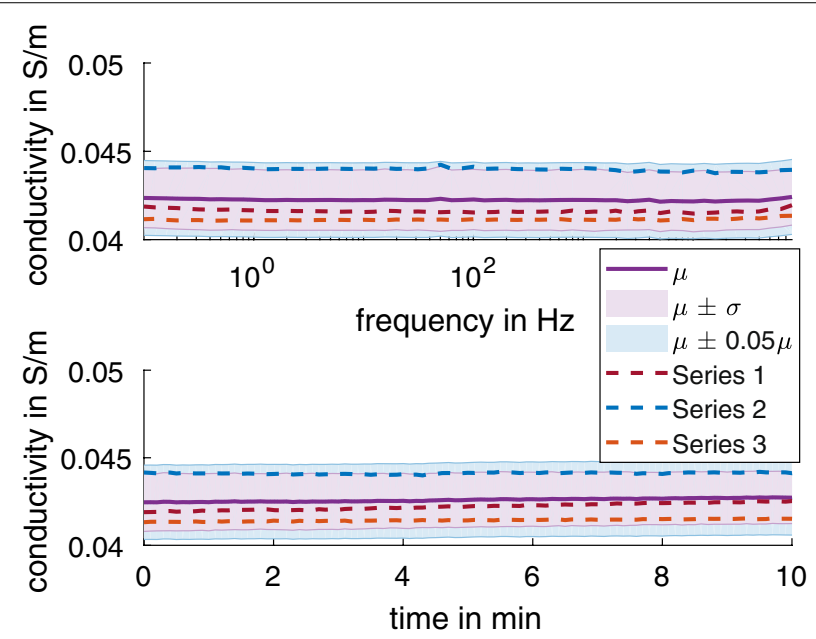

Fig. 5 The average conductivity of the gypsum sample with $\mathrm{NaCl}$ in the casting compound from three series of measurements (color-coded dashed lines) in $0.17 \% \mathrm{NaCl}$ solution adjusted to $25^{\circ} \mathrm{C}$ for (top) frequencies of $0.1 \mathrm{~Hz}$ to $100 \mathrm{kHz}$ and (bottom) $1 \mathrm{~Hz}$ for $10 \mathrm{~min}$. The shaded regions show $\mu \pm \sigma$ (purple) and $\mu \pm 0.05 \mu$ (blue) for comparison

$0.1 \mathrm{~Hz}$ to $100 \mathrm{kHz}$ (Fig. 7a) and duration of $60 \mathrm{~min}$ at $10 \mathrm{~Hz}$ (Fig. 7b). Series of measurements were repeated with $6 \mathrm{~h}$ between series 1 and 2, 24 h between series 2 and 3, and series 3 and 4 , and 36 h between series 4 and 5 .

The conductivity in longitudinal direction was found to stay consistent, with $0.32 \mathrm{~S} / \mathrm{m} \pm 0.003 \mathrm{~S} / \mathrm{m}$ in the frequency range of $0.1 \mathrm{~Hz}$ to $100 \mathrm{kHz}$ and $0.32 \mathrm{~S} / \mathrm{m} \pm 0.02 \mathrm{~S} / \mathrm{m}$ at $10 \mathrm{~Hz}$ over $60 \mathrm{~min}$ at $25^{\circ} \mathrm{C}$. The conductivity in transverse direction was found to stay consistent, with $0.12 \mathrm{~S} / \mathrm{m} \pm 0.003 \mathrm{~S} / \mathrm{m}$ in the frequency range of $0.1 \mathrm{~Hz}$ to $100 \mathrm{kHz}$ and $0.12 \mathrm{~S} / \mathrm{m} \pm 0.001 \mathrm{~S} / \mathrm{m}$ at $10 \mathrm{~Hz}$ over $60 \mathrm{~min}$ at $25^{\circ} \mathrm{C}$. These conductivity differences between longitudinal and transverse direction resulted in a conductivity anisotropy ratio of $1: 2.7 \pm 0.05$ in the frequency range of $0.1 \mathrm{~Hz}$ to $100 \mathrm{kHz}$ and 


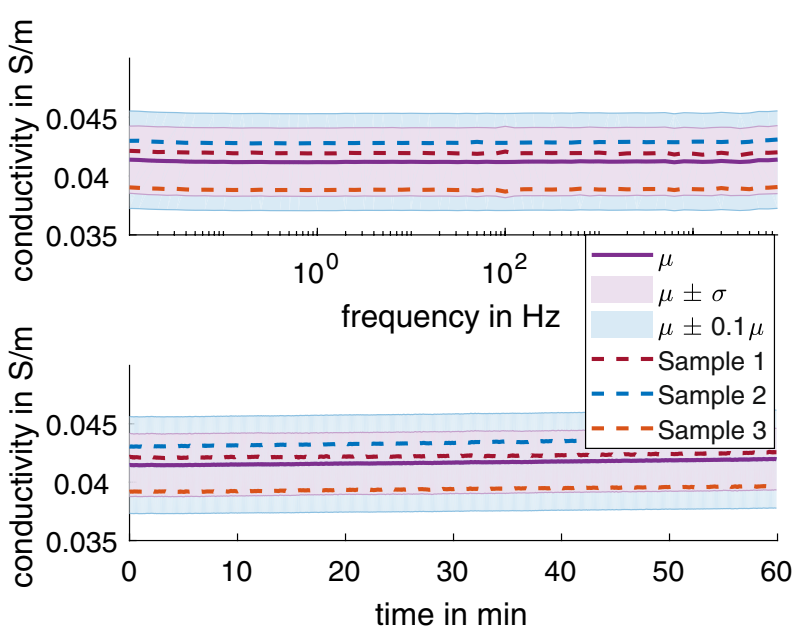

Fig. 6 The average conductivity of gypsum with $\mathrm{NaCl}$ in the casting compound in $0.17 \% \mathrm{NaCl}$ solution at $25^{\circ} \mathrm{C}$ for the (top) extended frequency range of $0.01 \mathrm{~Hz}$ to $100 \mathrm{kHz}$ and (bottom) extended duration of $60 \mathrm{~min}$ at $10 \mathrm{~Hz}$. The dashed line shows the data for each sample as color-coded. The shaded regions show $\mu \pm \sigma$ (purple) and $\mu \pm 0.05 \mu$ (blue) for comparison

1:2.8 \pm 0.02 at $10 \mathrm{~Hz}$ over $60 \mathrm{~min}$. Again, the spike at $50 \mathrm{~Hz}$ in the spectra (Fig. 7b) was likely due to power-line interference. The noise level was generally higher for frequencies above approximately $300 \mathrm{~Hz}$.

\section{Discussion}

In this study, we investigated the feasibility of establishing a realistically shaped and multi-compartmental head phantom, incorporating realistic electrolyte conductivity levels based on a $0.17 \% \mathrm{NaCl}$ solution using agar hydrogel, gypsum, and reed sticks.

The $0.17 \% \mathrm{NaCl}$ solution demonstrated a conductivity of $0.33 \mathrm{~S} / \mathrm{m}$ at $25{ }^{\circ} \mathrm{C}$ which corresponds to the value that is widely used to model the conductivity of intracranial volume [10]. Consequently, this saline solution established the fundamental electrolyte concentration that prevailed throughout all compartments. In a closed phantom design, the saline solution itself can be used to model the intracranial volume. Interior structures for signal generation (dipoles) or measurement (electrodes) can be inserted into the aqueous solution without interfering with the structure of this compartment.

Doping the $\mathrm{NaCl}$ solution with agarose as a solidifying agent enabled the formation of a mechanically durable scalp layer. The conductivity value of the agar hydrogel decreased on average by $7 \%$ ( $2 \mathrm{wt} \%: 5.5 \%, 3 \mathrm{wt} \%: 9.0 \%, 4 \mathrm{wt} \%: 6.3 \%$ ) compared to the pure $\mathrm{NaCl}$ solution. The variations in conductivity over time and frequency after multiple repetitions were well within $\mu \pm 0.05 \mu$. The average measured conductivity of $0.31 \mathrm{~S} / \mathrm{m}$ at $25^{\circ} \mathrm{C}$ is equivalent to $0.4 \mathrm{~S} / \mathrm{m}$ at $37{ }^{\circ} \mathrm{C}$ when linearly extrapolated, which was acceptable per Burger and van Milaan [23], reporting a conductivity of $0.435 \mathrm{~S} / \mathrm{m}$ at $37{ }^{\circ} \mathrm{C}$. Further, our measured average conductivity was within the range of $0.137 \mathrm{~S} / \mathrm{m}$ to $2.1 \mathrm{~S} / \mathrm{m}$ summarized by McCann et al. [8]. Adapting the agar concentration in the range of $2 \%$ to $4 \%$ allows the modification of its mechanical durability without changing the conductivity to values outside of the acceptable range. With an agar concentration of $4 \%$, applications such as EEG experiments using dry multi-pin electrodes become feasible [24]. 

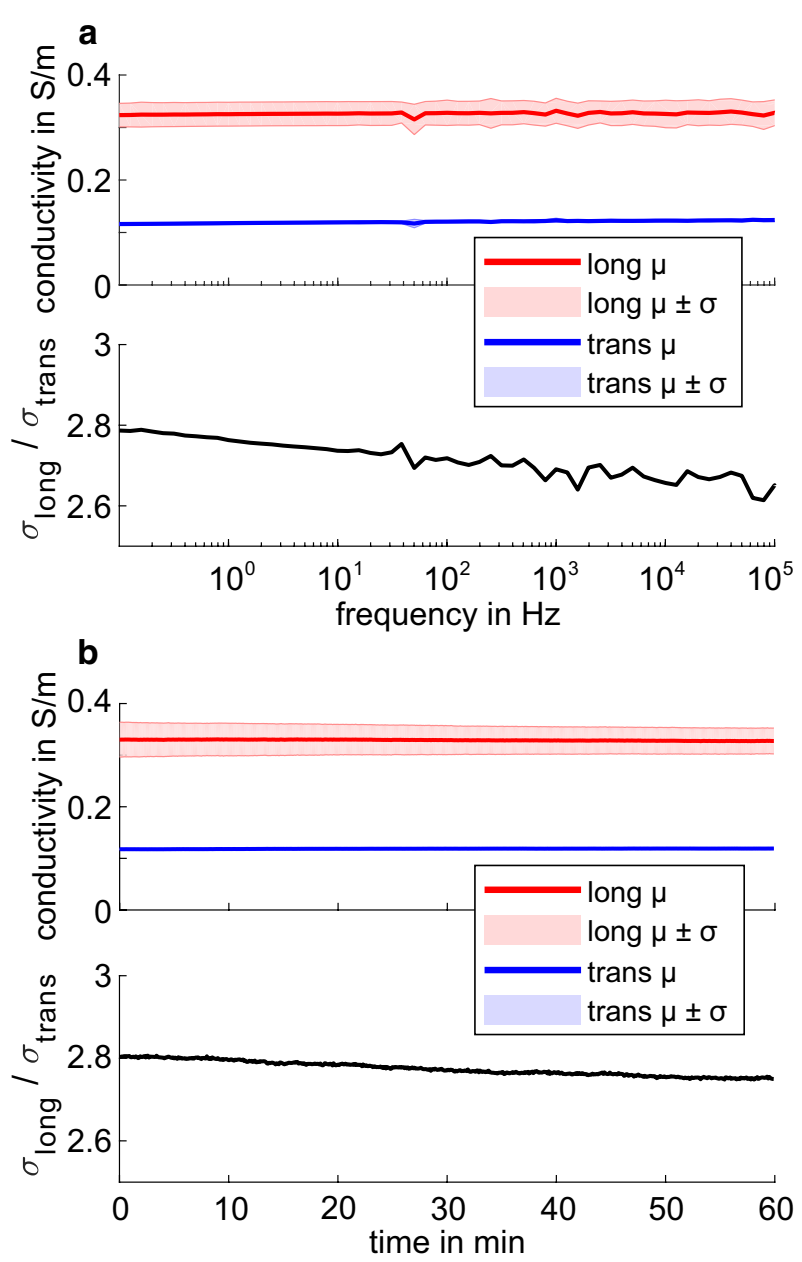

Fig. 7 The (top) average conductivity and (bottom) anisotropy ratio of reed sticks in $0.17 \% \mathrm{NaCl}$ solution at $25^{\circ} \mathrm{C}$ for $\mathbf{a}$ frequencies of $0.1 \mathrm{~Hz}$ to $100 \mathrm{kHz}$ and $\mathbf{b}$ duration of $60 \mathrm{~min}$ at $10 \mathrm{~Hz}$. The shaded regions show $\mu \pm \sigma$ for data in longitudinal (red) and transverse (blue) direction

The tested gypsum material demonstrated a considerable conductivity barrier. The two tested material configurations, with $0.17 \% \mathrm{NaCl}$ in the casting compound and without $\mathrm{NaCl}$ in the casting compound, covered a wide range of skull conductivities, varying from $0.00275 \mathrm{~S} / \mathrm{m}$ [11] to $0.066 \mathrm{~S} / \mathrm{m}$ [12] according to literature.

After an initial soaking of the sample in $\mathrm{NaCl}$ solution during the first measurement, the gypsum produced without $\mathrm{NaCl}$ (with deionized water only) in the casting compound provided stable results within a margin of $\pm 5 \%$ of $\mu$ over the tested frequency range and time interval as well as across measurement repetitions. The measured average conductivity value of $0.0017 \mathrm{~S} / \mathrm{m}$ at $25^{\circ} \mathrm{C}$ for the gypsum without $\mathrm{NaCl}$ in the casting compound is equivalent to $0.0024 \mathrm{~S} / \mathrm{m}$ at $36.5^{\circ} \mathrm{C}$ when linearly extrapolated, which was in the same order of magnitude with skull conductivity values of $0.0038 \mathrm{~S} / \mathrm{m}$ at $36.5^{\circ} \mathrm{C}$ reported by Tang et al. [25], who used a very similar setup with their samples immersed in saline solution.

The gypsum samples which were produced with a $0.17 \% \mathrm{NaCl}$ solution in the casting compound provided stable results within a margin of $\pm 5 \%$ of $\mu$ across multiple 


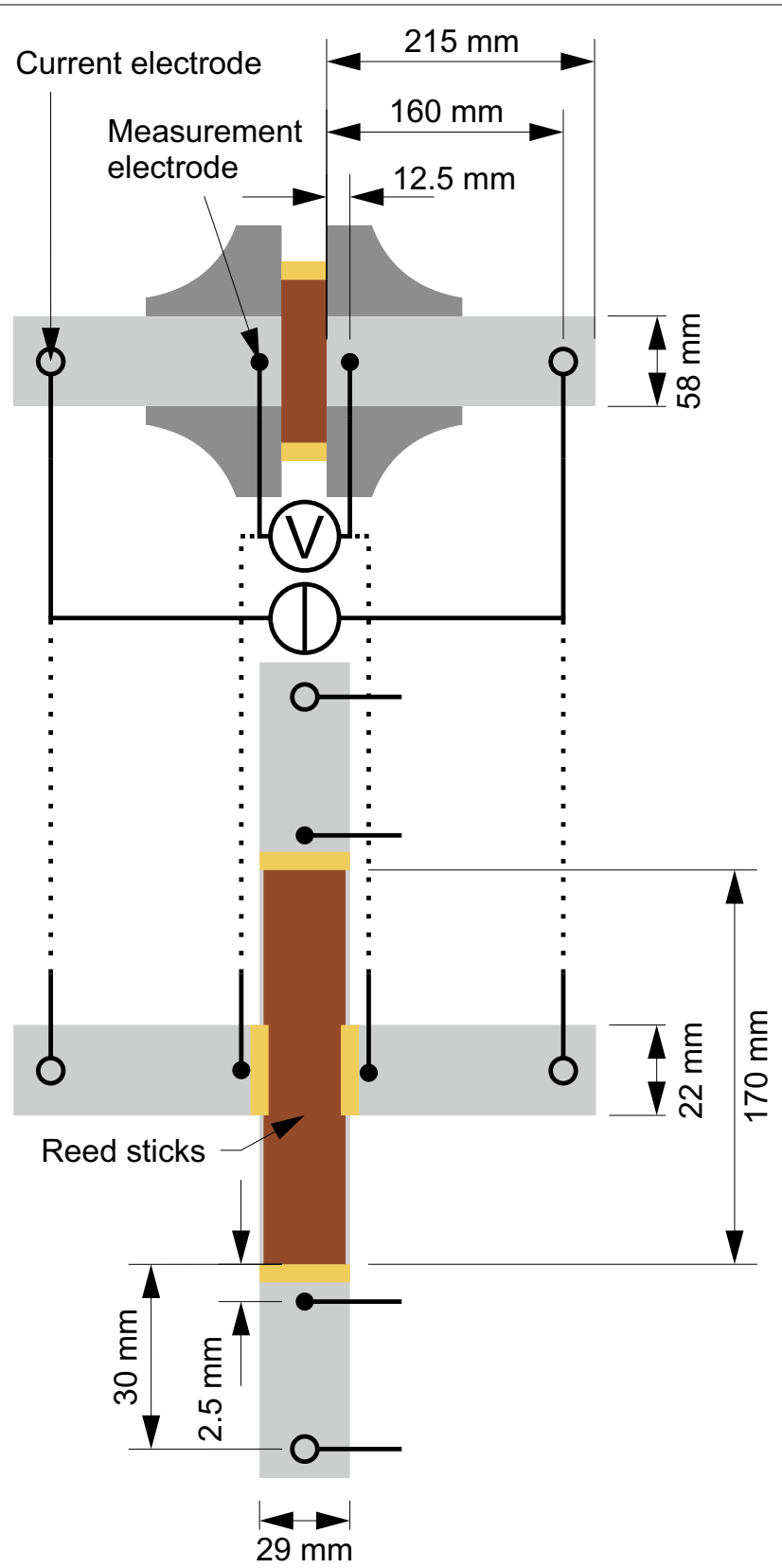

Fig. 8 Measurement schemes for isotropic (top) and anisotropic (bottom) impedance measurements. The cell with a material sample (brown) in plastic tubes filled with $\mathrm{NaCl}$ solution (light gray) incorporates the paired measurement electrodes (black filled dots) and the outer electrode pair (black outlined dots) for current application, both being connected to the Gamry Reference 600 Plus impedance analyzer. Sealing rings (yellow) and POM flanges (dark gray) complete the setup (adapted from [31])

measurement series and was reproducible between multiple samples within a margin of $\pm 10 \%$ of $\mu$. The measured average conductivity value of $0.0425 \mathrm{~S} / \mathrm{m}$ at $25{ }^{\circ} \mathrm{C}$ is equivalent to $0.063 \mathrm{~S} / \mathrm{m}$ at $37{ }^{\circ} \mathrm{C}$ when linearly extrapolated, which was in good accordance with skull conductivity range from $0.03 \mathrm{~S} / \mathrm{m}$ to $0.08 \mathrm{~S} / \mathrm{m}$ measured at $37{ }^{\circ} \mathrm{C}$ reported by Hoekema [26]. This gypsum as skull model and other phantom materials presented here 
established a skull-to-soft tissue conductivity ratios of 1:8, in close relation to the ratio of 1:12 reported by Oostendorp et al. [27].

The anisotropy ratio of approximately 1:3 implemented by the reed sticks is in good accordance with the ratio of 1:3 indicated in a diffusion tensor imaging data driven modeling approach [13], even though this ratio is below the white matter anisotropy ratio of 1:9 reported from earlier measurements [15]. Within a physical head phantom, reed sticks could be used to model white matter anisotropy. The sticks embody a solid model material not depending on complex support structures. Thus, they can be placed easily inside the compartment of the intracranial volume and used to model an anisotropic internal compartment.

A physical head phantom build from the materials characterized in the present study can realize the widely used approximation of the head as volume conductor comprising intracranial volume, skull, and scalp [9]. The electrolyte conductivity in all analyzed materials is based on a $0.17 \% \mathrm{NaCl}$ solution. Consequently, the multi-compartmental phantom incorporating these materials possesses a practically stationary ion concentration. Thus, the limitation of transient conductivity configurations due to diffusion processes across compartments with varying ion concentration [2, 28, 29] can be overcome.

All materials used to manufacture the samples in this study were commercially available. Using these products and standardized production procedures, we can ensure reproducibility of the phantom production. However, all samples have been manually produced and sample properties, i.e., the area A and the thickness/length d, used in Eq. 2 had tolerances influencing the calculated conductivity values. Further, the geometry parameters of the measurement cell, reflected in the cell constant, affected the results of the temperature compensation according to Eq. 1. Impedance measurements were conducted at room temperature in a non-air-conditioned environment, and measured values were afterwards converted to the reference temperature of $25{ }^{\circ} \mathrm{C}$ [30] for comparability.

The conductivities resulting from measurements with the four-electrode setup demonstrated high reproducibility with a coefficient of variation $(\mathrm{CV})$ of $0.8 \%$ and reliability with a difference of $0.2 \%$ when compared to values obtained with the ProfiLine Cond 3310.

The tested materials demonstrate consistent results when measured across several days. Consequently, head phantoms assembled with these materials have the potential of being stable throughout multi-day experiments.

\section{Conclusion}

We investigated the applicability of $\mathrm{NaCl}$ solution, agar hydrogel, and gypsum for modeling intracranial volume, scalp, and skull in physical head phantoms. Agar hydrogel and gypsum are well-known moldable materials that are available at low cost and inherently mechanically stable and permeable for ions. Our measurements showed that gypsum provides a stable conductivity barrier that implements physiologically plausible skull conductivity values in contact with $\mathrm{NaCl}$ solution. With reed sticks, we introduced a potential material with conductive anisotropy for physical phantoms. We conclude that gypsum is suitable for producing a hollow skull compartment and can be coated with agar hydrogel realistically mimicking the scalp layer. Both materials can have varying 
thicknesses in the range of $1 \mathrm{~mm}$ to $10 \mathrm{~mm}$, supporting realistic phantom construction for EEG, MEG, TES, and CDI.

\section{Materials and methods}

Sodium chloride solution

For reference purposes, we used $\mathrm{NaCl}$ (Sodium chloride $\geq 99 \%$, Carl Roth $\mathrm{GmbH}+\mathrm{Co}$. KG, Karlsruhe, Germany) to prepare the electrolyte solutions for providing the charge carrier in the physical head phantom. The conductivity of the sodium chloride solution was tested with a ProfiLine Cond 3310 (Xylem Analytics Germany Sales GmbH \& Co. KG, Weilheim, Germany).

\section{Agarose}

We applied agarose (Agarose Broad Range, Carl Roth GmbH + Co. KG, Karlsruhe, Germany) as a solidifying agent in the $\mathrm{NaCl}$ solution with sufficient concentration to yield the mechanical strength of synthetic skins. We added $2 \mathrm{wt} \%, 3 \mathrm{wt} \%$, and $4 \mathrm{wt} \%$ agarose to the heated electrolyte solution (approx. $65{ }^{\circ} \mathrm{C}$ ) while stirring constantly. The milky dispersion was heated to approx. $80^{\circ} \mathrm{C}$ until a clear solution emerged. The agarose electrolyte solution was kept in the liquid state, at around $65^{\circ} \mathrm{C}$, until poured into the casting mold. After cooling to room temperature, the agarose electrolyte solution formed a mechanically stable hydrogel.

\section{Gypsum}

In gypsum, the solid crystal embodies a structural conductivity barrier. We selected Stewaform (Glorex $\mathrm{GmbH}$, Rheinfelden, Germany) as casting compound in order to allow the formation of a realistic skull-shaped compartment. The Stewaform powder was mixed with either deionized water or $0.17 \% \mathrm{NaCl}$ solution in the ratio of 2:1 to form a casting compound and poured in negative molds of the desired form and let dry at $40{ }^{\circ} \mathrm{C}$ for $2 \mathrm{~h}$. To protect the gypsum structures from dissolving when coming in contact with the $\mathrm{NaCl}$ solution, we infiltrated the gypsum for one minute in a two-component epoxy resin XTC-3d (Smooth-On Inc., Macungie, PA, USA) at a ratio of 2:1 (epoxy resin:hardener). The gypsum was then dried again at $40^{\circ} \mathrm{C}$ for $10 \mathrm{~min}$.

\section{Reed sticks}

We fit 80 reed sticks (diffusor sticks, Jörn Poppenhäger, Ottweiler, Germany) into a hollow plastic tube with an inner diameter of $29 \mathrm{~mm}$ and a length of $170 \mathrm{~mm}$. In the middle, the tube incorporated two circular cut-outs with a diameter of $21 \mathrm{~mm}$. Pellet and ring electrodes (MedCaT GmbH, Munich, Germany) were attached to the tube in $2.5 \mathrm{~mm}$ and $30 \mathrm{~mm}$ distance to the opening, respectively (cf. Fig. 8 bottom). The tube including the electrode configurations was tightly sealed with silicone and the whole volume was filled with $0.17 \% \mathrm{NaCl}$ solution.

\section{Impedance measurements}

We tested the electrical properties of the material samples including agar hydrogel, gypsum, and reed sticks by means of four-electrode impedance measurements at room temperature. The temperature was monitored by a Traceable Excursion-Trac (VWR 
International bvba, Leuven, Belgium). The impedance of the measurement cell comprising the material sample clamped between two $\mathrm{NaCl}$ solution compartments with a concentration of $0.17 \% \mathrm{NaCl}$ in deionized water was measured using a Gamry Reference 600 Plus (Gamry Instruments, Warminster, PA, USA) (Fig. 8). The $\mathrm{NaCl}$ solution compartments held an outer pair of silver/silver chloride ring electrodes with a distance of $160 \mathrm{~mm}$ to the sample for impressing an electric current, and an inner pair of silver/ silver chloride electrodes with $4 \mathrm{~mm}$ diameter for measuring the resulting potential difference. A more detailed description of the setup can be found in [31]. The reed sticks were tested in the above-mentioned double-tube configuration.

We tested the impedance of $0.17 \% \mathrm{NaCl}$ solution $(n=3)$, agarose hydrogels with $2 \mathrm{wt} \%$ $(n=3), 3 \mathrm{wt} \%(n=3)$, and $4 \mathrm{wt} \%(n=3)$ agarose and each one gypsum sample with and without $0.17 \% \mathrm{NaCl}$ solution in the casting compound. The gypsum samples were also tested three times using this procedure after they have been dried at ambient air for at least $20 \mathrm{~h}$. Each series of measurements were carried out over the frequencies of $0.1 \mathrm{~Hz}$ to $100 \mathrm{kHz}$ and for $10 \mathrm{~min}$ at $1 \mathrm{~Hz}$. There was a 30-min pause between each series of measurements.

Further, we tested three samples of agarose hydrogels with $2 \mathrm{wt} \%$ agarose and one gypsum sample with $0.17 \% \mathrm{NaCl}$ solution in the casting compound on an extended frequency range of $0.01 \mathrm{~Hz}$ to $100 \mathrm{kHz}$ and for an extended duration of $60 \mathrm{~min}$ at $10 \mathrm{~Hz}$. There was a 6-h pause between each series of measurements.

Simultaneous to measuring the impedances, we measured the temperature in the cell with an electrically insulated stainless steel probe connected to a Traceable ${ }^{\circledR}$ ExcursionTrac (VWR International bvba, Leuven, Belgium).

\section{Conductivity calculation}

The experimental measurements were carried out at ambient temperatures. To compare to existing literature values, the measured values were adjusted for the temperature difference. First, the impedance of the cell containing only $\mathrm{NaCl}$ solution, $Z_{\mathrm{NaCl}}$, was measured to use as the reference. The impedance can then be adjusted using

$$
Z_{25}=\frac{Z_{\text {meas }}-Z_{\mathrm{NaCl}}}{1+\alpha \cdot\left(\vartheta_{\text {meas }}-25^{\circ} \mathrm{C}\right)},
$$

where $Z_{25}$ is the impedance adjusted to $25^{\circ} \mathrm{C}, Z_{\text {meas }}$ is the measured impedance, $\vartheta_{\text {meas }}$ in ${ }^{\circ} \mathrm{C}$ is the temperature at the time of measurement, and $\alpha$ is the linear factor (also called cell constant). The cell constant was determined through measurements of a cell containing $0.17 \% \mathrm{NaCl}$ solution only. The material conductivity is computed from the temperature-compensated net impedance $Z_{25}$ using:

$$
\kappa=\frac{d}{Z_{25} \cdot A},
$$

where $d$ is the material sample thickness/length and $A$ is the surface area. The tube configuration loaded with the reed sticks was measured in longitudinal and transverse direction. For both directions, we calculated the conductivity according to (2) with $Z_{25}$ obtained from (1). The conductivity anisotropy was calculated as the ratio between longitudinal and transverse conductivity. 


\section{Acknowledgements}

The authors thank Danae Crascovscaia for support during data acquisition.

\section{Authors' contributions}

AH essentially contributed to the conception of the study, the data acquisition, processing and analysis, and the manuscript drafting and revision. RM essentially contributed to the data acquisition, the interpretation of data, and the manuscript revision. JH essentially contributed to the conception of the study, the interpretation of data, and the manuscript revision. All authors read and approved the final manuscript.

\section{Funding}

Open Access funding enabled and organized by Projekt DEAL. This project has received funding from the European Union's Horizon 2020 research and innovation programme under grant agreement No. 686865 (project BREAKBEN), from the Free State of Thuringia under 2017 VF 0035 and 2018 IZN 004 co-financed by the European Union under the European Regional Development Fund (ERDF), from the German Research Foundation under Grant Number HA 2899/21-1, and from the Carl Zeiss foundation.

\section{Availability of data and materials}

All data generated or analyzed during this study are included in this published article.

\section{Ethics approval and consent to participate}

Not applicable.

\section{Consent for publication}

Not applicable.

\section{Competing interests}

The authors, $\mathrm{AH}, \mathrm{RM}$, and $\mathrm{JH}$, declare that they have no competing interests.

\section{Author details}

${ }^{1}$ Institute of Biomedical Engineering and Informatics, Faculty of Computer Science and Automation, Technische Universität IImenau, 98693 IImenau, Germany. ${ }^{2}$ Biomagnetic Center, Department of Neurology, Jena University Hospital, 07743 Jena, Germany.

Received: 24 August 2020 Accepted: 7 November 2020

Published online: 23 November 2020

\section{References}

1. Hunold A, Funke ME, Eichardt R, Stenroos M, Haueisen J. EEG and MEG: Sensitivity to epileptic spike activity as function of source orientation and depth. Physiol Meas. 2016;37:1146-62.

2. Wetterling F, Liehr M, Schimpf P, Liu H, Haueisen J. The localization of focal heart activity via body surface potential measurements: Tests in a heterogeneous torso phantom. Phys Med Biol. 2009;54:5395-409.

3. Hömmen P, Mäkinen AJ, Hunold A, Machts R, Haueisen J, Zevenhoven KCJ, et al. evaluating the performance of ultra-low-field MRI for in-vivo 3D current density imaging of the human head. Front Phys. 2020.

4. Hunold A, Haueisen J, Ahtam B, Doshi C, Harini C, Camposano S, et al. Localization of the epileptogenic foci in tuberous sclerosis complex: a pediatric case report. Front Hum Neurosci. 2014;8:1-12.

5. Peterchev AV, Wagner TA, Miranda PC, Nitsche MA, Paulus W, Lisanby SH, et al. Fundamentals of transcranial electric and magnetic stimulation dose: Definition, selection, and reporting practices. Brain Stimul. 2012;5:435-53. https:// doi.org/10.1016/j.brs.2011.10.001.

6. Vorwerk J, Cho JH, Rampp S, Hamer H, Knösche TR, Wolters $\mathrm{CH}$. A guideline for head volume conductor modeling in EEG and MEG. Neuroimage. 2014;100:590-607.

7. Aydin Ü, Vorwerk J, Küpper P, Heers M, Kugel H, Galka A, et al. Combining EEG and MEG for the reconstruction of epileptic activity using a calibrated realistic volume conductor model. PLOS ONE. 2014;9:e93154. https://doi. org/10.1371/journal.pone.0093154.

8. McCann H, Pisano G, Beltrachini L. Variation in reported human head tissue electrical conductivity values. Brain Topogr. 2019;32:825-58

9. Stenroos M, Hunold A, Haueisen J. Comparison of three-shell and simplified volume conductor models in magnetoencephalography. Neuroimage. 2014;94:337-48.

10. Geddes LA, Baker LE. The specific resistance of biological material-a compendium of data for the biomedical engineer and physiologist. Med Biol Eng. 1967;5:271-93.

11. Homma S, Musha T, Nakajima Y, Okamoto Y, Blom S, Flink R, et al. Conductivity ratios of the scalp-skull-brain head model in estimating equivalent dipole sources in human brain. Neurosci Res. 1995;22:51-5.

12. Wendel K, Narra NG, Hannula M, Kauppinen P, Malmivuo J. The influence of CSF on EEG sensitivity distributions of multilayered head models. IEEE Trans Biomed Eng. 2008;55:1454-6.

13. Güllmar D, Haueisen J, Reichenbach JR. Influence of anisotropic electrical conductivity in white matter tissue on the EEG/MEG forward and inverse solution A high-resolution whole head simulation study. Neuroimage. 2010;51:145-63.

14. Wolters CH, Anwander A, Tricoche X, Weinstein D, Koch MA, MacLeod RS. Influence of tissue conductivity anisotropy on EEG/MEG field and return current computation in a realistic head model: A simulation and visualization study using high-resolution finite element modeling. Neuroimage. 2006;30:813-26.

15. Nicholson PW. Specific impedance of cerebral white matter. Exp Neurol. 1965;13:386-401. 
16. Baillet S, Rira JJ, Main G, Magin JF, Aubert J, Ganero L. Evaluation of inverse methods and head models for EEG source localization using a human skull phantom. Phys Med Biol. 2001;46:77-96.

17. Leahy RM, Mosher JC, Spencer ME, Huang MX, Lewine JD. A study of dipole localization accuracy for MEG and EEG using a human skull phantom. Electroencephalogr Clin Neurophysiol. 1998;107:159-73.

18. Kim D, Jeong J, Jeong S, Kim S, Jun SC, Chung E. Validation of computational studies for electrical brain stimulation with phantom head experiments. Brain Stimul. 2015;8:914-25. https://doi.org/10.1016/j.brs.2015.06.009\%5Cnpa pers3://publication/doi/10.1016/j.brs.2015.06.009.

19. Jung Y-J, Kim J-H, Kim D, Im C-H. An image-guided transcranial direct current stimulation system: a pilot phantom study. Physiol Meas. 2013;34:937-50. https://stacks.iop.org/0967-3334/34/i=8/a=937?key=crossref.d74fe62408 c40afdd46c161acec4f413

20. Liehr M, Haueisen J. Influence of anisotropic compartments on magnetic field and electric potential distributions generated by artificial current dipoles inside a torso phantom. Phys Med Biol. 2008;53:245-54.

21. Lide DR. CRC Handbook of Chemistry and Physics, 93rd Edition. In: Haynes WM, Lide DR, Bruno TJ, editors. Handb Chem Phys [Internet]. CRC Press; 2012. p. 5-73. https://books.google.com/books?hl=fr\&lr=\&id=-BzP7Rkl7Wk C\&pgis $=1$

22. Schwan HP, Ferris CD. Four-electrode null techniques for impedance measurement with high resolution. Rev Sci Instrum. 1968;39:481-5.

23. Burger HC, Milaan, van JB. Measurements of the specific Resistance of the human Body to direct Current. Acta Med Scand. 1943;114:584-607.

24. Fiedler P, Muhle R, Griebel S, Pedrosa P, Fonseca C, Vaz F, et al. Contact pressure and flexibility of multipin dry EEG electrodes. IEEE Trans Neural Syst Rehabil Eng. 2018;26:750-7.

25. Tang C, You F, Cheng G, Gao D, Fu F, Yang G, et al. Correlation between structure and resistivity variations of the live human skull. IEEE Trans Biomed Eng. 2008:55:2286-92.

26. Hoekema R, Wieneke GH, Leijten FSS, Van Veelen CWM, Van Rijen PC, Huiskamp GJM, et al. Measurement of the conductivity of skull, temporarily removed during epilepsy surgery. Brain Topogr. 2003;16:29-38.

27. Oostendorp TF, Delbeke J, Stegeman DF. The conductivity of the human skull: Results of in vivo and in vitro measurements. IEEE Trans Biomed Eng. 2000;47:1487-92.

28. Sadleir RJ, Neralwala F, Te T, Tucker A. A controllably anisotropic conductivity or diffusion phantom constructed from isotropic layers. Ann Biomed Eng. 2009;37:2522-31. https://doi.org/10.1007/s10439-009-9799-6.

29. Tenner U, Haueisen J, Nowak H, Leder U, Brauer H. Source localization in an inhomogeneous physical thorax phantom. Phys Med Biol. 1999:44:1969-81. https://stacks.iop.org/0031-9155/44/i=8/a=309?key=crossref.4b006336a8 66caad04db7e7e10705853

30. ISO/TC 147/SC 2, Physical chemical and biochemical methods. ISO 7888:1985(R2017) Water quality - Determination of electrical conductivity. Int. Organ. Stand. 1985.

31. Hunold A, Strohmeier D, Fiedler P, Haueisen J. Head phantoms for electroencephalography and transcranial electric stimulation: a skull material study. Biomed Tech. 2018;63:647-55.

\section{Publisher's Note}

Springer Nature remains neutral with regard to jurisdictional claims in published maps and institutional affiliations.

- fast, convenient online submission

- thorough peer review by experienced researchers in your field

- rapid publication on acceptance

- support for research data, including large and complex data types

- gold Open Access which fosters wider collaboration and increased citations

- maximum visibility for your research: over $100 \mathrm{M}$ website views per year

At BMC, research is always in progress.

Learn more biomedcentral.com/submissions 